\section{Memorias, significados y olvidos en la construcción social del patrimonio ferroviario del Sur de Chile $^{*}$}

Memories, meanings and oblivion in the social construction of the railway heritage of Southern Chile

\section{Rosa María Guerrero ${ }^{* *}$}

\section{Resumen}

El artículo busca aportar al debate sobre los diversos usos y significados contemporáneos

Los resultados y antecedentes de este artículo son producto del proyecto de Investigación FONDECYT No 11130335. PATRIMONIO CULTURAL, TERRITORIO Y DESARROLLO LOCAL": Identificación y análisis de procesos de territorialización del discurso patrimonial, su articulación con políticas públicas y efectos en las dinámicas de desarrollo local en tres regiones del sur de Chile (2013-2016). Financiado por la Comisión Nacional de Investigación Científica y Tecnológica de Chile .CONICYT. Parte de los antecedentes expuestos son resultado de la investigación "Memorias del ramales ferroviarios del Biobío. Historia, memorias y propuestas para su puesta en valor". CNCA. 2013.

** Departamento de Urbanismo. Fac. de Arquitectura, Urbanismo y Geografía. FAUG. Universidad de Concepción. Chile. rosaguerrero@udec.cl. del patrimonio cultural, a partir del análisis de los principales hitos y significados que nutren los procesos de construcción social del patrimonio ferroviario en tres regiones del sur de Chile. Se destaca la diversidad de memorias ferroviarias y sus distintos roles en las actuales acciones en torno al patrimonio ferroviario. Se subraya la instalación del modelo neoliberal como un hito central de las memorias de los actores ferroviarios, que sin embargo permanece ausente de los relatos y acciones contemporáneas. Finalmente, se analiza el rol complejo de la empresa de ferrocarriles y de los actores públicos en la orientación de los actuales procesos de patrimonialización ferroviaria y los nudos y proyecciones de los mismos a nivel local.

Palabras clave: patrimonio ferroviario, historia, memorias colectivas, identidades, neoliberalismo.

\section{Abstract}

This article aims to contribute to the debate on the various uses and contemporary meanings of cultural heritage, from the analysis of the main landmarks and meanings, about the processes of social construction of the railway heritage in three regions of Southern Chile. The diversity of railway memories and their different roles in current actions around this legacy are especially emphasized. The installation of the neoliberal model as a central landmark of memories of railway actors is stressed, something which nevertheless remains absent from the contemporary actions and stories. Finally, the complex role of the railway company and the public actors in the orientation of the 
current railway heritagisation processes, and the projections and junctions of them at local level, are analyzed.

Keywords: railway heritage, history, collective memories, identities, neoliberalism.

\section{Introducción: La construcción social del Patrimonio Ferroviario}

Las regiones del sur de Chile, al igual que otras regiones del país, construyeron su identidad y su desarrollo económico y social en torno al ferrocarril. Los inicios del ferrocarril en la región del Biobío y más al sur datan de mediados del siglo XIX (Astorquiza 1929). No obstante, pese a los recursos y esfuerzos que implicó la instalación de las vías e infraestructura ferroviaria y el impacto positivo que tuvo para las comunidades, a mediados de los años ochenta se inició un proceso de privatización que implicó el cierre de muchos ramales, especialmente los más pequeños y económicamente menos rentables. Es así que la infraestructura ferroviaria fue poco a poco deteriorándose y desapareciendo.

Desde hace una década, no obstante, se ha producido en Chile una revalorización social del ferrocarril, fundamentalmente a la luz de la relevancia que ha tomado a nivel social y público el patrimonio cultural (Guerrero 2012; Ballart 1997). Esto se ha expresado en el surgimiento de diversas acciones de recuperación, preservación, gestión y puesta en valor del patrimonio ferroviario ${ }^{1}$. Considerando

En los últimos 10 años han aumentado considerablemente los proyectos de preservación y puesta en valor del patrimonio cultural y natural de base local en Chile, entre ellos los vinculados a patrimonio ferroviario. Ver. Politica Cultural del Chile. 2011-2016. lo anterior se llevó a cabo un estudio que se propuso como uno de sus objetivos el análisis del estado, significados y acciones locales en torno al patrimonio ferroviario de las regiones del Biobío, la Araucanía y Los Ríos. Para responder estos objetivos, nuestro primer desafío fue conceptualizar lo que entendíamos por patrimonio ferroviario.

El concepto de Patrimonio Ferroviario se entiende regularmente asociado al patrimonio industrial. Concepto acuñado a mediados del siglo XX para dar cuenta del valor histórico y cultural de gran cantidad de infraestructura industrial obsoleta y abandonada que evidenciaban el fin del periodo industrial y la instalación de la época post-industrial en los países de occidente. Los vestigios materiales representativos de la era industrial: fábricas, herramientas o maquinarias, pese a tener un carácter funcional y casi repetitivo en sus formas, se consideraban evidencia de una época, de un proceso socio-histórico que era singular para cada territorio. Por ello se debía resguardar, preservar y darle usos sociales que permitieran su puesta en valor y conservación. En el caso del ferrocarril, alude principalmente a bienes tales como estaciones, vías, rieles, túneles, vagones. etc. Esta dimensión del patrimonio ferroviario, su materialidad, es la que está con frecuencia más relevada en las acciones de la institucionalidad pública y de los actores sociales en torno al patrimonio ferroviario. De hecho, el imaginario de la puesta en valor del patrimonio ferroviario está muy asociado al turismo y a la idea de un tren antiguo remodelado recorriendo las antiguas vías. Chile no es ajeno a esta tendencia. No obstante la materialidad, pese a ser relevante como testimonio y como elemento aglutinador de memorias, no da cuenta por sí misma de los 
procesos y significados asociados a la misma. La piedra o el vestigio no tienen valor patrimonial en sí mismo, su valor como tal es resultado de un proceso de valorización social (Giménez 2005). En este marco lo relevante del patrimonio material no es los vestigios recuperados y su puesta en valor, sino la historia y memoria recuperada con ello. Como plantea Casennelles (2007), lo relevante del patrimonio industrial o ferroviario es la historia y el testimonio que contienen sobre una comunidad y un lugar; eso es lo que lo diferencia de otros patrimonios similares. Esto no quiere decir que develar, describir, inventariar, proteger o preservar la materialidad no sea relevante, lo es, en la medida que son reservorios de la memoria, compartimentos donde ésta se activa y aglutina. El rescate y preservación de lugares de la memoria en el caso de las violaciones a los derechos humanos, como expresa Jelin (2001) o Ricoeur(2004), son un importante ejemplo de ello.

No obstante, los conflictos y debates sociales en torno a la puesta en valor del patrimonio cultural (García 1987; Guerrero 2012), han evidenciado los diversos sentidos y efectos que las acciones de patrimonialización tienen para distintos actores sociales, más allá de su rentabilidad económica o de su proyección como objeto o bien.

En este marco, desde ya hace un tiempo, existe un cierto consenso en las ciencias sociales del carácter procesual y dinámico del patrimonio cultural (Prats, 2004). En el entendido que son elementos del pasado de una comunidad, una herencia o tradición que es considerada valiosa, pero es una apropiación presente del pasado. Es un pasado actualizado y vivo. Cada comunidad enriquece y adiciona sentido a sus expresiones consideradas patrimoniales en función de sus necesidades y demandas actuales. Lo patrimonial es por lo tanto siempre un proceso incremental y dinámico que sólo es posible entenderlo bajo el marco de la experiencia y memoria actual (Prats 2004; Ricoeur 2004)

Tradicionalmente las elites políticas han sido las principales creadoras de patrimonios, los patrimonios nacionales surgen a la luz de la construcción de una idea de nación (Florescano 1994; García 1999). Es lo que Halbwachs (2004), llama tradiciones inventadas. Tradiciones que luego pasan a ser apropiadas por las comunidades y ser validadas como expresión de su identidad, sin dejar de acotar que siguen siendo patrimonios hegemónicos (Cirese 2005), que buscaban en gran medida homogeneizar la cultura y las identidades (Pérez 2000).

Paralelamente, existen también los patrimonios informales, que existen como expresiones significativas de una identidad comunitaria, y que no están formalizados o sacralizados como tales por las elites en el poder. En algunos casos los gobiernos formalizan ciertos patrimonios con posterioridad a que estos sean valorados por sus comunidades, los reconocen como tales, pero este reconocimiento no es necesario para que estos sean elementos relevantes para la comunidad a la que representan. Son patrimonios "vivos" (Giménez 2005) fuertemente vinculados a la vida e identidad de una comunidad. Como plantea Prats (2004), la construcción patrimonial es un proceso de arriba hacia abajo y también viceversa. Este carácter procesual y bidireccional implica que el patrimonio es generalmente un escenario de conflicto y disputa por la legitimidad social, en el entendido que son expresiones fuertemente arraigadas a un territorio, como elementos 
presentes y significativos ${ }^{2}$. Recoger los sentidos en torno a estas categorías implica entonces analizar los diversos imaginarios y nudos que están en la base de su construcción en cada contexto sociocultural.

En este marco definimos 4 dimensiones ejes de análisis del patrimonio ferroviario: hitos históricos en torno al ferrocarril, vestigios materiales, memorias ferroviarias y acciones sociales en torno al patrimonio ferroviario. El análisis de estas cuatro dimensiones se llevó a cabo a partir de diversos acercamientos metodológicos. Para la primera, se revisaron archivos locales, regionales y nacionales disponibles y se aplicaron entrevistas en profundidad a expertos. Para la segunda se realizaron recorridos por ramales e infraestructura en desuso y se revisaron archivos locales, generando archivos fotográficos y topográficos. Para la tercera dimensión, se aplicaron entrevistas en profundidad a actores relevantes y se desarrolló un ejercicio de activación de la memoria colectiva llamado "mapas de la memoria ferroviaria". Para la última dimensión, se recogieron y analizaron las principales acciones en torno al patrimonio ferroviario desarrolladas en los últimos años en las zonas de estudio, a partir de entrevistas con ejecutores, se describieron los significados asociados a las distintas acciones. A continuación se exponen algunos de los antecedentes y reflexiones más relevantes recopiladas en las distintas regiones de estudio: Biobío, Araucanía y Los Ríos.

Se destaca a partir del análisis anterior la importancia de la instalación del modelo

Se entiende el territorio, como una construcción socio-simbólico, no sólo como un espacio político -administrativo. En Giménez Gilberto (2005). Teoría y análisis de la Cultura, México: Ed. Conaculta, vol. I. neoliberal en Chile como un hito central en la desaparición de gran parte del patrimonio ferroviario material. Se subraya también el relegamiento de las memorias ferroviarias en los diversos procesos de recuperación, preservación y puesta en valor del patrimonio hoy en día. Finalmente se analiza el rol complejo de la empresa de ferrocarriles en los procesos de patrimonialización ferroviaria y en las proyecciones de los mismos.

\section{Los hitos históricos del patrimonio ferroviario en los territorios del sur de Chile}

El Ferrocarril fue uno de los inventos de la era industrial que más impacto causó en las economías locales y nacionales. La regiones del sur configuraron su identidad e historia ligada a éste, el cual, al igual que en otros contextos, vino de la mano con el proceso de industrialización, en el caso de Biobío, específicamente con el crecimiento de la minería del carbón en Lota y con el desarrollo portuario ${ }^{34}$. En 1855 se realizó la extensión de las líneas al Sur (Alliende 1997; Guajardo 2007), señala, que a diferencia de la motivación económica que tuvieron particulares extranjeros para levantar el primer ferrocarril en Chile en el Norte, la construcción de las líneas del Valle Central y sur de Chile se sustentó más en propósitos políticos, específicamente la idea de vincular al territorio nacional como parte de una estrategia político- desarrollista coordinada desde el Estado, cuál era la integración del territorio nacional (Ibarra 2004). La experiencia del tren en las regiones del sur no sólo fue

ASTORQUIZA Octavio. Cien Años del Carbón de Lota 1852-1952. Cía. Carbonera e Industrial de Lota. 1952.

ETCHEPARE Jaime. Et. Al. Historia de Curanilahue, la búsqueda de un destino. Universidad de Concepción. Concepción.1986 
relevante por su impacto económico y las posibilidades de desarrollo e industrialización, sino también como experiencia de vida (Bernard 2010). Con el tren se movilizaron recursos, productos, personas, se abrieron caminos, se poblaron lugares, se crearon empresas, sociedades, inversiones internacionales, etc. Pero además de esto el tren, especialmente en los lugares donde se levantaron estaciones o paraderos, aportó en la construcción de muchas historias locales y en la transformación de comunidades, dinamizando sus identidades, dotándolas de pertenencia, pero a la vez interviniendo sus territorios y mundos.

\begin{abstract}
"Mire, el tren vino a hacer una revolución inmensa en toda esa gente en el año 1910. Cuando, comprenderá usted, que a Chillán no llegaba todavía un automóvil ni camión. Como en el año 1915 aparecieron los primeros autos, pero en Chillán sí. Y los camiones acá llegaron en el año 1929. De tal manera que el tren fue una cosa extraordinaria en sus vidas, fue así como un descubrimiento científico para la gente. Porque antes viajaban en carreta a vender sus... mi abuelo, por ejemplo." (L. Yáñez, historiador local)
\end{abstract}

Los ramales eran líneas férreas que comunicaban a las zonas alejadas, en la cordillera o la costa, con la vía principal del ferrocarril. La llegada de un ramal a un pueblo lejano les cambiaba la vida a los habitantes, pues traía consigo las noticias y las mercancías de otros lugares, pero además para muchos pueblos y poblados de las distintas regiones fue la posibilidad de conectarse con el mundo y salir de su aislamiento (Basterrica 2010).

Iba a Chillán la gente, a las compras, sus menestras, a las ferreterías, en fin...los dueños de animales iban a Chillán también, iban en tren, ¿Ya? Y mandaban sus animales a veces por el tren también, en coche de animales, ¿Ya? Negocios, se hacían negocios ahí, más menos esa era la idea. Ahora, el día domingo iba mucha gente a Recinto, porque era tan lindo y tan bonito el paisaje, lleno de colorido, de naturaleza autóctona, de árboles nativos, en fin, de todo..." (L. Yáñez, historiador local)
Las estaciones fueron además importantes espacios de sociabilidad para las comunidades. La llegada y salida de los trenes determinaba los tiempos de la colectividad y gran parte de las actividades de las mismas. Los barrios cercanos a las estaciones configuraban una trama social y cultural particular que daba vida al entorno (Cartes 2011).

Los viajes en tren, que en general eran extremadamente largos por la aún deficiente tecnología, eran grandes odiseas para los que las realizaban lo que otorgaba una impronta especial al viaje. El Ramal LebuLos Sauces, era, por ejemplo, uno de los más complejos y dificultosos de la Región del Biobío, especialmente porque tenía bastantes pendientes y curvas, lo cual generaba que los trenes no pudieron transitar a mucha velocidad (Hermosilla 2002). A principios de la década de los 70, relata Thompson (2000), las velocidades autorizadas para todo el trazado no superaban los 60 km/hora. En el ramal Chillan- Recinto, por ejemplo, en la región del Biobío, había tramos donde el tren iba tan lento que los pasajeros se bajaban y caminaban a su lado mientras aprovechaban de comer moras $u$ otros frutos que estaban en el camino. ${ }^{5}$

La empresa de ferrocarriles no sólo fue relevante por su impacto como eje comunicador de los territorios, sino también por su impronta como empresa con fuerte orientación social. Acorde con otras empresas estatales del período, ferrocarriles otorgaba diversos beneficios sociales a sus trabajadores y a sus familias, lo cual significó que se le llamara "la madre empresa”. Esto condición cambió radicalmente con posterior a la dictadura de 1973.

Entrevista ex ferroviario Ramal Chillan-Recinto. 
El recorrido de los trenes de pasajeros por los ramales en las regiones del sur fue dejando de realizarse de manera progresiva desde mediados de los años setenta y se consolidó ya en los años ochenta. El impacto de este proceso para algunas comunidades fue brutal. No existe un consenso respecto a las razones de cese progresivo del ferrocarril ${ }^{6}$. No obstante, el definitivo ocaso del tren de pasajeros, su desmantelamiento y la desaparición de gran parte de la infraestructura mueble e inmueble del mismo, comenzó realmente a mediados de los ochenta con la reestructuración de la empresa.

El golpe del estado de 1973 y la instalación de un régimen dictatorial por 17 años, no sólo significó la pérdida de la democracia sino, fue el eje base para la instalación de un modelo económico neoliberal que rompió de raíz con el rol de bienestar del Estado que, hasta ese momento, había llevado a una ampliación progresiva de los derechos sociales y culturales de los grupos sociales más vulnerables. En la práctica esto se expresó en la privatización de gran parte de las empresas de carácter Estatal más importantes a nivel social: salud, educación y pensiones. Como también otras más estratégicas, como es el caso de Ferrocarriles del Estado. En 1979, EFE dejó de percibir el subsidio que anualmente

\footnotetext{
El argumento más común es que el cese del ferrocarril de pasajeros tenía que ver fundamentalmente con el alto costo de éste, tanto para mantención de las vías, como también para subsidiar el costo de los pasajes, aun cuando algunos plantean que en realidad era la deficiente gestión y la falta de tecnologías que fueran adaptándose a las nuevas demandas. Otro a factor a considerar fue la aparición de nuevos medios de transporte tales como buses de transporte de pasajeros y camiones de carga. Para Guajardo (2007) Pese a que el ferrocarril era superior en cuanto a seguridad, comodidad, no le fue fácil competir con la disponibilidad y rapidez de los otros servicios que poco a poco la comunidad fue prefiriendo.

Ninguna de estas razones son concluyentes, en algunos territorios pesaron más unas que otras
}

era entregado por el Estado, lo que llevó a la Empresa a enfrentar una serie de dificultades. Según Thompson (2000), la falta de subsidio vino a terminar con el rol social que el ferrocarril había cumplido.

Básicamente se cerraron los ramales menos rentables y se privatizó el servicio de carga ${ }^{7}$. La política de privatización apuntaba a delegar al mercado gran parte de la gestión de empresas estatales estratégicas (salud, educación, pensiones, transportes y energías) aduciendo generalmente para ello una deficiente gestión estatal. El argumento era que la entrada del mercado optimizaría recursos y haría más eficientes la entrega de los mismos, esto redundaría en beneficios para todos. Hoy después de casi 30 años de la privatización vemos que esto no fue así. En el caso de ferrocarriles significó desmantelar las vías ferroviarias en desuso y enajenar gran parte de los terrenos e infraestructuras ferroviarias.

\begin{abstract}
"Durante las últimas décadas el ferrocarril ha perdido participación frente al modo de transporte por carretera. Las deficiencias en la gestión, junto con una baja prioridad de las políticas de infraestructura y transporte, resultaron en un proceso de desinversión que derivó en una menor participación de mercado y pérdidas económicas para el sector". (CEPAL 2012: 26)
\end{abstract}

Para los trabajadores de ferrocarriles significó un cambio radical en sus condiciones de trabajo y junto con ello la pérdida de su prestigio y valoración social. Con la privatización se bajó de los 24.717 trabajadores que había en 1970

Según Thompson (2000), en este período el transporte por carretera ejerció una competencia "desleal", ya que los camiones de mayores dimensiones -que compiten con el transporte ferroviario- provocaban los mayores daños en la carretera. Este perjuicio no era cubierto con los impuestos y peajes que este gremio pagaba, lo que en cierta medida provocaba que el Estado indirectamente subvencionara también el transporte carretero. 
a 9.800 en 1980 y a sólo 6.801 en 1988 . Siendo despedidos de la empresa en 1995 alrededor de 4 mil más. Actualmente quedan alrededor de 1800 trabajadores (Polanco 2015:100).

Se negociaron los despidos y las jubilaciones anticipadas. Las condiciones de trabajo de los que quedaron fueron bajo el marco de una empresa privada perdiendo importantes beneficios sociales; similar situación a la que sufrieron los trabajadores portuarios y mineros en análoga época.

La radicalidad del proceso tuvo un profundo impacto en los empleados, sus familias, y las comunidades. Dado el importante valor simbólico, social y material que tenía el ferrocarril, muchos actores y comunidades sintieron esto como un "despojo" y como una afrenta a la comunidad y su identidad.

\begin{abstract}
"En el año 1986, más o menos en la madrugada, sentimos unos ruidos en la vía, ruidos como de máquinas que golpeaban las vías, la gente del pueblo se levantó y fue a ver. Había camiones y maquinas sacando las vías y durmientes, al consultarles por qué lo hacían, les dijeron que eran contratados por ferrocarriles del Estado para levantar la vía y llevársela. Esto provocó hondo malestar en la población, por cuanto sentían que esa vía era de ellos y que nadie les había informado de eso. Los pobladores hicieron lo mismo, comenzaron a llevarse parte de las vías (...) si había alguien que se iba a llevar las vías iban a ser ellos porque ellos las habían construido" (Entrevista habitante de Contulmo)
\end{abstract}

Las repercusiones económicas fueron importantes no sólo para los trabajadores directos sino para los lugareños y habitantes de los territorios dónde el tren circulaba. Hubo procesos económicos que surgieron a la par del tren y que con el cierre de los ramales se acabaron o debieron reciclarse, es el caso de las palomitas de Laraquete, mujeres que vendían sus tortillas con mariscos a los pasajeros del tren. La ruta 160 , reemplazó la antigua vía del tren, y las tortillas son vendidas en la carretera, no obstante se perdió el dinamismo y la identidad asociada al oficio.

"Todo cambió cuando se fue el tren, antes eran muchas
más, compartíamos, era una aventura ver llegar y partir
el tren, nos subíamos, conversábamos (...) ahora igual
vendemos, pero es más frío, más distante el trato.
(Entrevista, Palomita Laraquete).

\section{El patrimonio ferroviario material del sur de Chile}

Si entendiésemos el patrimonio ferroviario sólo como la herencia material asociada al ferrocarril, podríamos decir, de acuerdo a los datos recopilados, que el patrimonio en las regiones del sur de Chile es prácticamente inexistente. En las tres regiones de estudio (Biobío, Araucanía y Los Ríos) existe un importante deterioro y desaparición de la infraestructura y material ferroviario que ya no está en uso (que es la mayoría), ello es resultado fundamentalmente del proceso de privatización y desmantelamiento llevado a cabo por la empresa de ferrocarriles del Estado en la década de los ochenta y noventa, a lo cual hay que sumar el abandono y la apropiación privada del mismo. Los procesos de rescate y preservación del patrimonio ferroviario material, llevados a cabo generalmente por actores no gubernamentales, han sido escasos e insuficientes para preservar la importante infraestructura material en desuso, sobretodo porque no han contado con apoyos institucionales. Los que se han realizado, han sido en algunos casos procesos de denuncia y lucha, por lo cual no han estado exentos de conflictos.

"Se fueron todos [los bienes], las locomotoras, se fueron a Puente Alto y también a uno por acá por el sur, por ese 
ramal que da a Los Álamos, por ahí por Angol, que se mete por ahí para allá, por los Sauces, ahí en Arauco. Ahí fue a parar todo este material” (L. Yáñez, historiador local)

En el caso de Biobío, los vestigios que quedan son algunas estaciones en mal estado, algunos puentes y túneles. En la provincia de Arauco se concentran la mayoría de los túneles ferroviarios aún en pie. De éstos quizás el elemento más destacable es el túnel Nahuelbuta (Figura 1), que es un hito dada la importante hazaña que significó su construcción.

Figura1. Túnel Nahuelbuta. Contulmo.

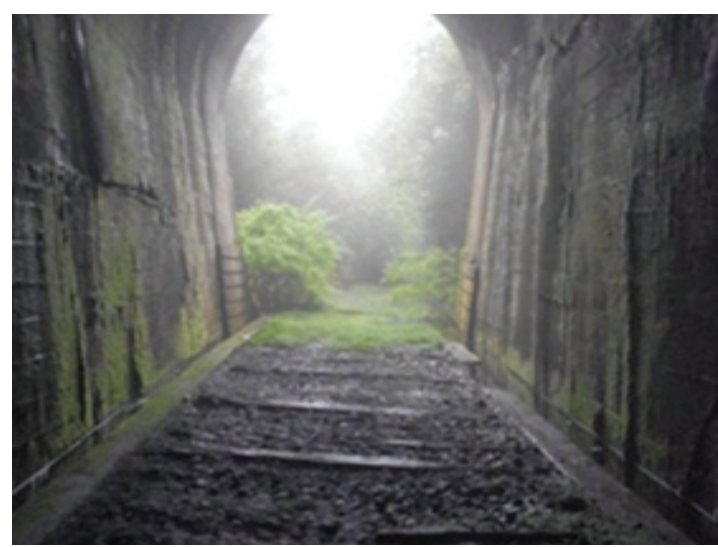

Fuente: proyecto "Memorias del ramales ferroviarios del Biobío. Historia, memorias y propuestas para su puesta en valor". CNCA. 2013.

En la Araucanía el panorama es diferente, dado que tiene un proyecto de preservación y puesta en valor del patrimonio ferroviario como es el museo ferroviario de Temuco que ha permitido la conservación de bastante material ferroviario, incentivando además la generación de una fuerte identificación de la ciudad con la historia ferroviaria. Las acciones en torno al museo han incentivado la recuperación y puesta en valor de diversos inmuebles y espacios vinculados al ferrocarril, como es la activación de los recorridos de corto alcance entre Temuco y ciudades aledañas, como también la implementación de diversos proyectos en torno al antiguo Barrio Estación, que circunda el museo. ${ }^{8}$

No obstante, al igual que las otras regiones, gran parte de la infraestructura de los ramales en desuso han desaparecido o están deterioradas. Importantes ramales fueron cerrados y desmantelados, como es el caso del ramal a Lonquimay en la región de la Araucanía o el ramal Valdivia- Antilhue en la región de los Ríos, que unía la ciudad con el interconectado central norte-sur. Este último dejó de funcionar en el año 1992, pero aún conserva la vía y parte de las estaciones, aunque en mal estado ${ }^{9}$. Sin embargo, a diferencia de Biobío las comunidades locales organizadas han defendido el ramal y desde el año 1996 han levantado un proyecto de recorrido turístico que pese a los conflictos con EFE, sigue adelante. Del ramal Valdivia- Osorno queda en buen estado la Estación de La Unión que fue refaccionada el 2005, las otras, como la de Rio Bueno se encuentran en mal estado.

Por encontrarse en su mayoría en manos privadas, es difícil saber en realidad cuál es la situación del patrimonio mueble, pero de acuerdo a la información recogida, gran parte ha ido también desapareciendo junto con la infraestructura. Parte importante de material ferroviario se comercializa en páginas web de ventas, tales como mercado libre y similar o bien en empresas concesionarias de Ferrocarriles

Entrevista Directora Museo Ferroviario Pablo Neruda. Temuco.

9 Grallert Felipe. Antilhue: ferrocarril, modo de vida y erradicación. AUS. Valdivia) n.14 Valdivia 2013 
como INVIA. Existen algunos pocos museos locales que posee algo de material ferroviario en exhibición, como es el caso del Museo Dunwunwe de Contulmo y el museo ferroviario de Temuco, generalmente vía donaciones de privados, pero estos casos son lo menos.

\section{Memorias e identidades ferroviarias del sur de Chile}

El patrimonio cultural no son solo vestigios e historia, sino también las memorias de ese pasado, entendido como el arraigo que éste tiene para una comunidad, y la re significación que las comunidades hacen del mismo a partir de su experiencia presente. No es solo acontecimiento sino testimonio, recuerdo. Las memorias en torno a la experiencia ferroviaria nos entregan elementos para comprender los vacíos de la historia, el relato nos actualiza los hechos pasados y los dota de sentido. Diversos actores activan y se apropian del pasado de manera diferenciada, los recuerdos no son comunes, se agrupan, no tienen el mismo significado para unos y otros. Todos recordamos, pero historias distintas. La memoria tiene un potencial hermenéutico, sugiere interpretaciones, atisba significados.

En el caso de las regiones de estudio, pese a la desaparición y deterioro de gran parte del patrimonio ferroviario material de las regiones en estudio, hay una importante memoria e identidad colectiva asociada al ferrocarril. Esta memoria se pluraliza y nos lleva a distintos actores con distintas "memorias", todas con sus diferencias, selecciones y omisiones, constituyen parte del patrimonio ferroviario. La memoria ferroviaria de los territorios en estudio se articula en torno a tres tipos de actores: los ex trabajadores del ferrocarril, los ex usuarios y los amantes del tren, cada uno de estos grupos recuerda y rescata elementos distintos de la historia ferroviaria, cada uno de estos grupos además desarrolla distintas acciones en torno a esta memoria.

La historia del ferrocarril, de sus hitos, contadas desde la memoria de estos distintos actores devela matices y omisiones de la historia escrita, se mueve entre los pliegues del olvido y de un futuro posible.

Los ex ferroviarios, memorias abatidas: Desde el cierre del ferrocarril existen distintas agrupaciones que han desarrollado acciones para mantener viva la memoria ferroviaria, fundamentalmente compuestas por ex trabajadores ferroviarios. Estas se movilizan no solo en pos de rescatar una historia o experiencia desde el olvido, sino también para dar cuenta que es una memoria presente que se proyecta hacia el futuro. No obstante, la ausencia de una expresión material donde cristalizar las memorias e identidades ferroviarias sin duda ha contribuido a hacer más difícil la permanencia y reconstrucción de las mismas.

Los ex ferroviarios son un grupo que poseen una fuerte identidad que los une y reúne de manera periódica. En la mayoría de los casos han pasado ya casi 30 años que dejaron de trabajar en la empresa de ferrocarriles, pero se reúnen aún en las mismas sedes sociales en las cuales lo hacían cuando trabajaban en ésta. Pese a esta frecuencia y persistencia de reunirse, las memorias de estos actores las hemos definido como memorias abatidas o inmóviles porque son fundamentalmente espacios para la evocación y la necesidad de nombrar hechos, pero no de elaborar acciones de puesta en valor o de difusión hacia la comunidad. 
En el caso de estos actores las memorias se organizan en torno a tres principales ejes o hitos: a) Memorias vinculadas a los recorridos de los distintos ramales; b) Memorias en torno a su experiencia como trabajadores; $y$ c) Memorias del proceso de privatización y desmantelamiento del ferrocarril.

Estos actores tienen muy vivos los recuerdos de su vivencia ferroviaria. Poseen un cúmulo riquísimo de antecedentes históricos, anécdotas y experiencias de vida sobre el ferrocarril. Su relatos evidencian la complejidad y dureza de la vida ferroviaria, pero también del rol gravitante que el ferrocarril jugaba para las comunidades, ya sea transportando materias primas o pasajeros. ${ }^{10}$

Figura 2. Mapas de la memoria ferroviaria Ramal Rucapequen. Biobío

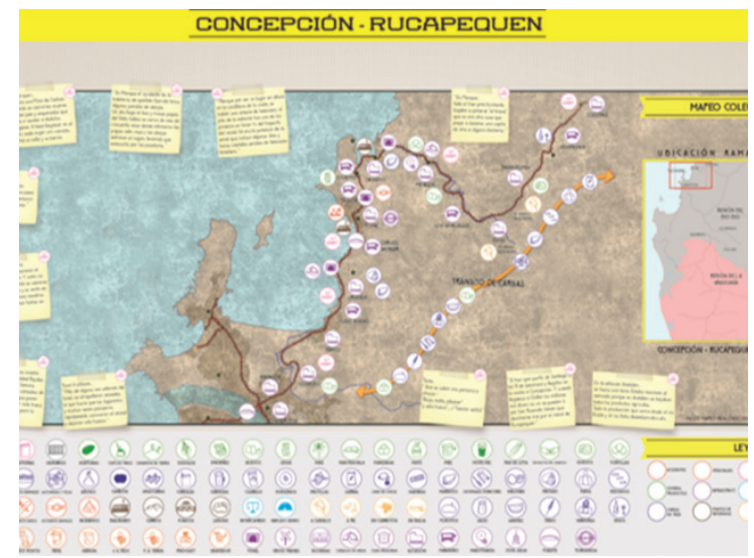

Fuente: proyecto "Memorias del ramales ferroviarios del Biobío. Historia, memorias y propuestas para su puesta en valor". CNCA. 2013

Taller Mapa de las Memorias de los Ramales del Biobío con ex ferroviarios de la Región.
Dado como se desarrolló el proceso de término del ferrocarril y desmantelamiento de la empresa de ferrocarriles y de su infraestructura, estos actores sienten que la memoria ferroviaria es una memoria que ha sido también desmantelada, violentada, tiene por ello un fuerte componente crítico tanto hacia ellos mismos como trabajadores y su rol en la defensa del ferrocarril, como también hacia el Estado, organizador y gestor del proceso de privatización tanto en dictadura como posterior a ésta.

\footnotetext{
"es que es penoso que hubiéramos llegado a esto, porque ferrocarril hoy en día no tiene un futuro. Se ha mirado mucho comercial, antiguamente la empresa era un servicio de bien, ahora no po, ahora es una empresa comercial. [Era accesible para todos], el Estado lo subsidiaba [...] y con el gobierno con Pinochet, jodimos porque Pinochet dijo "ya, ferrocarriles se las arregla por su cuenta, ustedes verán cómo se las arreglan". Pasó que ferrocarriles empezó a enajenar, a vender, a vender. (...) Para la empresa, el cambio con el gobierno militar fue negativo, porque no se vio progreso. Todo lo contrario, empezamos a desmoronarnos por falta de recursos" (Don Rolando, trabajador de ferrocarril por 20 años)
}

La memoria de los ex ferroviarios es una memoria que se ha visto también erosionada por la falta de espacios y expresiones materiales donde cristalizar sus recuerdos y discursos. Sin duda que la presencia de un espacio o materialidad donde afincar las memorias es importante para mantener la identidad presente. Por eso existe una demanda latente y constante por recuperar los vestigios desmantelados: estaciones, vías, paraderos, maquinarias, vagones, etc. Por ello algunos miembros participan en organizaciones orientadas al rescate de vestigios ferroviarios $y$ maquinarias. Es una forma, no solo de objetivar la memoria y darle visibilidad, sino también de relevar su identidad de cara a los otros. Como plantean autores como Jelin (2000) o Halbwachs (2001), la memoria se inscribe en una materialidad, en espacios y lugares específicos 
donde se reconocen los grupos activos en la sociedad.

No obstante, pese a la ausencia de materialidad la memoria de estos actores persiste y se mantiene como un elemento central de su identidad. En este caso además la memoria cumple una función de cohesión social, de integración, otorgando elementos para proyectarse colectivamente como grupo. Sin embargo, no genera movilización, incentiva la necesidad de conectarse entre ellos, de conocer y compartir, pero no de desarrollar acciones que generen cambios o que pongan en valor el patrimonio del que ellos son parte.

Ex usuarios y amantes del tren, memorias movilizadas: Las memorias ferroviarias no son patrimonio de los ex trabajadores, son un elemento relevante de la construcción y mantención de la identidad de otros actores del territorio, los cuales, sin ser ex trabajadores se siente también identificados con el ferrocarril y el rol de éste en el desarrollo de las comunidades. Estos son tanto ex usuarios como amantes de los trenes y de la cultura asociada a la misma.

En el caso de estos actores, las memorias están asociadas a la vida que transcurría en y alrededor del tren, como parte de un periodo personal y social de sus vidas, en el rol social y cultural del mismo, en cómo otorgó cierta impronta a una comunidad. Hasta hoy hay en las comunidades muchas personas que utilizaron el tren en sus desplazamientos cotidianos, todos tienen una nostalgia por lo que fue el tren, pero también una fuerte demanda porque este regrese. La mayoría destaca los beneficios del tren por sobre los buses. Plantean que el tren no es una cosa del pasado, sino del presente y del futuro, también lo ven así los ex ferroviarios y simpatizantes, es una memoria presente compartida.

Los amigos o amantes del tren, no necesariamente fueron usuarios, pero su interés o identidad con los trenes no está marcada por la experiencia sino por la valorización de la importancia de este medio de transporte para la comunidad y en un gusto personal por este tipo de medios de transporte. Los que se sitúan en estos grupos son los que han desarrollado más acciones de rescate y puesta en valor del patrimonio ferroviario. Algunos de ellos se agrupan en la Asociación Chilena de Conservación del Patrimonio Ferroviario. ${ }^{11}$ Entidad que surge precisamente a la luz de los procesos de privatización y desmantelamiento del ferrocarril en los años ochenta. Estos actores, de variados oficios y profesiones, tienen en común el amor y el gusto por los trenes, y en ausencia de un Estado que proteja y preserve la infraestructura ferroviaria, se han constituido en las última década en actores relevantes para la preservación del patrimonio ferroviario inmueble y mueble: vagones, locomotoras, salas de máquinas, archivos y otra gran cantidad de material ferroviario abandonado o a punto de perderse. Su capacidad de actuación y resultados, así como la visibilidad de sus acciones varían de una región a otra.

\section{Acciones y prácticas de patrimonialización ferroviaria en los territorios locales del sur de Chile}

Las acciones en torno al patrimonio ferroviario en las regiones de estudio, en general, no han

Entrevistas representantes Asociación Chilena de Conservación del patrimonio Ferroviario de Biobío y los Ríos. 
sido numerosas, respecto a otros patrimonios, básicamente porque tienden a entenderse vinculadas a una expresión material, y como hemos visto más arriba éstos no son numerosos. Pese a ello algunas se destacan como acciones importantes a nivel regional y nacional, como es el caso del Museo Pablo Neruda, y del Tren a Antilhue. En las comunidades más pequeñas las acciones han sido parceladas, y el apoyo institucional a las mismas ha sido precario. En general las principales acciones en torno al patrimonio ferroviario las podemos agrupar en:

\section{a. Acciones de rescate de material ferroviario por parte de actores locales:}

La mayoría de estas acciones han sido realizadas desde mediados de los años ochenta, cuando EFE dejó de establecer medidas de seguridad en los antiguos recintos de la empresa. Han sido ejecutadas fundamentalmente por organizaciones de ex ferroviarios o grupos de interés en el tema. De los cuales los más activos son la Asociación Chilena de Conservación del Patrimonio Ferroviario. (ACHCPF). Actores que durante largo tiempo y muchas veces sin esperar autorización de EFE han rescatado máquinas y materiales para protegerlos, especialmente cuando era evidente el riesgo de su desaparición o desmantelamiento. Muchas de sus acciones se han realizado casi al borde la ilegalidad, pero gran cantidad de material y maquinaria ferroviaria que aún está en pie hoy, ha sido gracias a las acciones de estos grupos.

La motivación central de estas acciones es evitar el deterioro de la infraestructura ferroviaria por considerarla una evidencia del importante rol de este medio de transporte en los territorios. evidenciar y sensibilizar a la comunidad sobre

Figura 3. Vagón de Ferrocarril utilizado por la Agrupación Cultural del Patrimonio de Tomé

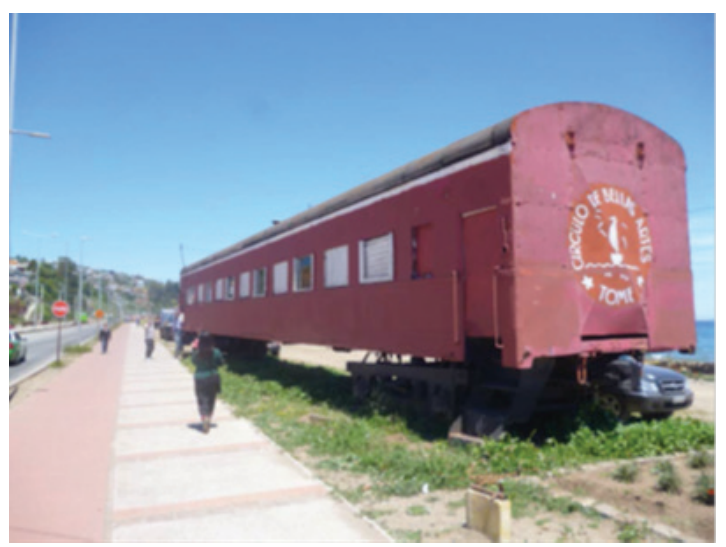

Fuente: proyecto FONDECYT №11130335.

la desaparición de este importante medio de transporte. No obstante, lo que estas organizaciones en muchos casos no han podido asegurar es la preservación o puesta en valor de los bienes rescatados, los que en algunos casos han sido recuperados y traslados, pero han seguido deteriorándose en otros espacios

\section{b. Acciones de documentación, y recopilación de antecedentes históricos.}

Estas acciones han sido realizadas mayormente por agrupaciones culturales, educativas, académicos y actores locales interesados en la historia ferroviaria, básicamente lo que se ha realizado aquí es recopilar antecedentes y material gráfico de la historia del ferrocarril en los pueblos de las distintas regiones. El trabajo si bien es cierto ha sido relevante no ha sido homogéneo, habiendo lugares donde se encuentra mucha información y en otras muy pocas. La información refiere fundamentalmente 
a los principales hitos de algunas comunidades en torno al ferrocarril. Se incluyen aquí una gran diversidad de documentos escritos y fotografías que han rescatado las experiencias, sucesos y representaciones respecto al ferrocarril en las comunidades de estudio. En la mayoría de los casos estas recopilaciones son los insumos para otras acciones locales. Las motivaciones para estas acciones son fundamentalmente evidenciar el valor que el ferrocarril tuvo para una comunidad y para el desarrollo económico y social de ésta.

\section{c. Acciones de puesta en valor del patrimonio:}

Se entiende por acciones de puesta en valor aquellas que se orientan a recuperar, sensibilizar y difundir la historia y memoria ferroviaria al interior de una comunidad. Estas acciones han sido de dos tipos. Con fines educativos, de divulgación, sensibilización y recuperación de la historia y memoria ferroviaria hacia la comunidad, como es el caso de las caminatas al túnel ferroviario de Lebu, actividad que es realizada como parte de actividades educativas del municipio o bien actividades del museo Ferroviario Pablo Neruda de Temuco, que desde el año 2004 desarrolla formalmente actividades de puesta en valor y difusión de la historia ferroviaria. En este marco también podemos incluir las acciones de la Red de Educadores Patrimoniales de los Ríos, que desde su inicio llevan a cabo acciones educativas para difundir y educar a la comunidad de la región de los Ríos en el conocimiento y preservación de su patrimonio cultural.

Un segundo grupo de actividades de puesta en valor ha sido con fines turísticos, orientados a visitantes, externos a la comunidad, como es el caso de los circuitos a los túneles de
Contulmo (Figura 4), el tren de Antilhue o el tren turístico del museo ferroviario Pablo Neruda, así como el proceso de reactivación de los barrios ferroviarios en ambos casos. Podemos agrupar aquí también la recuperación y remodelación de la antigua vía a Lonquimay para ser habilitada como ciclo vía y vía peatonal, entre otras.

Figura 4. Recorrido Túnel Contulmo.

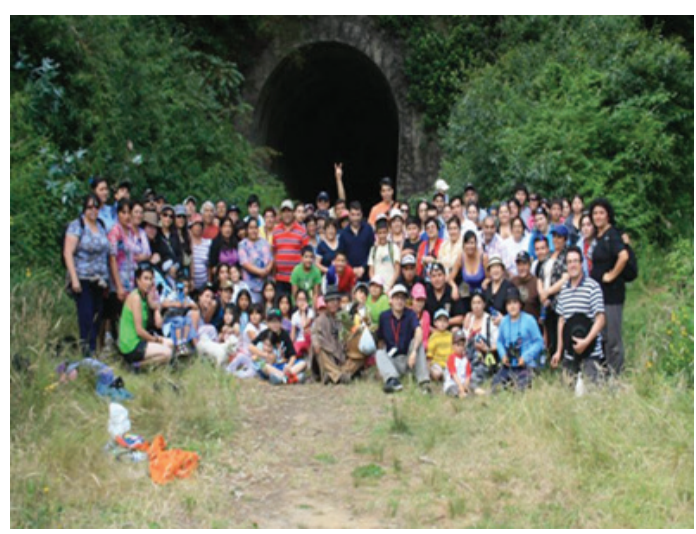

Fuente: proyecto "Memorias del ramales ferroviarios del Biobío. Historia, memorias y propuestas para su puesta en valor". CNCA. 2013.

En el caso de la Araucanía y Valdivia, las acciones se concentran en proyectos emblemáticos ubicados en las capitales regionales, tal como el Museo Ferroviario de Temuco y el Tren de Antilhue, ambos cuentan con un importante respaldo de la comunidad local y regional y son proyectos consolidados.

Ahora una pregunta relevante, es en qué medida estas acciones incorporan los discursos e hitos que los actores ferroviarios (ex trabajadores, ex usuarios y asociaciones ferroviarias) develan como relevantes en la historia y memoria 
ferroviaria. En general en las acciones más institucionales, especialmente las orientadas al turismo, estos hitos en torno a la historia ferroviaria, como la implantación del modelo neoliberal y la privatización y desmantelamiento de la empresa y sus consecuencias, el rol social que tenía la empresa, etc, es omitido, se destacan fundamentalmente los hitos vinculados a la llegada del ferrocarril, su relevancia para el desarrollo de los territorios y las comunidades y aspectos anecdóticos. En las acciones locales, menos institucionalizadas, sin embargo, estos elementos surgen con bastante recurrencia, pero no tienen mayor impacto a nivel comunitario por cuánto son acciones parceladas y con bajo apoyo. Son los actores patrimoniales de asociaciones de defensa del patrimonio ferroviario o ex usuarios, en conjunto con actores culturales y académicos, los que más acciones han realizado en ese sentido.

\section{Reflexiones finales: implicancias y proyecciones de los procesos de patrimonialización ferroviaria}

Si entendemos el patrimonio ferroviario desde una concepción integral, como un sistema y proceso que incluye aspectos históricos, memorias y vestigios vistos y actualizados por actores social y culturalmente territorializados, entendemos que éste es mucho más que unos vestigios materiales y un relato de los hitos de la historia del ferrocarril. El patrimonio como proceso y como relación social, tal como ha sido recogido en este artículo, nos permite develar las diversas dinámicas sociales que han configurado las memorias y practicas patrimoniales de una comunidad. Desde este enfoque el análisis de los procesos de patrimonialización nos permite recoger los diversos usos y significados en torno a estos procesos y develar el carácter polisémico de los mismos. En este marco es que ha sido posible revelar las claves sociopolíticas que están en la base de estos procesos, los conflictos sociales asociados, las dinámicas de construcción social del olvido y la creciente mercantilización de las identidades y la historia.

A nivel histórico, el proceso de privatización de ferrocarriles y de externalización de sus servicios y bienes, realizado en los años ochenta, como parte de una dinámica mayor de instalación de un modelo económico y político neoliberal, fue el proceso que impulsó el cierre de muchos ramales, en su mayoría de trenes de pasajeros hacia localidades interiores de las regiones del sur de Chile, por ser considerados "poco rentables". Al hacerlo se abandonó gran parte de la infraestructura material, la cual o bien fue desmantelada por la propia empresa y vendida, o bien comenzó un lento deterioro y desaparición por obra del olvido y de la apropiación privada.

A nivel social y cultural la privatización significó que fueron despedidos gran parte de los trabajadores. Este proceso generó un profundo impacto en los trabajadores ferroviarios, en sus familias y en las economías locales, pero también en el imaginario social en torno a la empresa estatal. A nivel local la radicalidad de este cambio fue muy fuerte, fundamentalmente por la importancia que el ferrocarril tuvo para el desarrollo y la identidad de muchas comunidades. El ferrocarril abrió nuevas vías de comunicación, creo comunidades, incentivó procesos de reactivación económica y actividades culturales. En este marco, el cierre de ramales y su posterior desmantelamiento fragmentó la trama social, cultural y económica 
que se había configurado en torno a este medio de transporte.

En cada territorio, el cambio de modelo de gestión ferroviaria, ha sido una experiencia difícil de procesar a nivel social. La radicalidad de proceso, ha hecho que estos episodios se organicen como sedimentos en la memoria de los grupos, los cuales, dependiendo del impacto de la experiencia, lo elaboran con menor o mayor complejidad. Las memorias de los ex ferroviarios, es una memoria dolida, inmóvil, no ha generado acciones que permitan sacar a la luz los sentidos y conflictos, son memorias que se recluyen y se aíslan, constituyéndose en referentes para la elaboración y preservación de una identidad basada en el trauma en el quiebre. Por su nivel de implicancia en el proceso de privatización de la empresa, son memorias dolidas, que se han inmovilizado por la nostalgia, el desencanto, pero que permanecen para dar sentido al presente de una colectividad.

Los ex usuarios y participantes de asociaciones simpatizantes del ferrocarril, probablemente por su menor implicancia, son memorias activas, nostalgias que surgen y se fortalecen con el ánimo de rescatar y recuperar los vestigios materiales como evidencia más palpable de la memoria ferroviaria, una memoria que ellos conciben como un elemento central para urdir sentido a la experiencia social presente, como recordatorio de un tiempo donde primaban otros valores que se busca recuperar $y$ difundir en los entresijos de las locomotoras y las vías recuperadas. Los actores de estas organizaciones han sido los que han llevado a cabo las principales acciones de puesta en valor del patrimonio ferroviario de los distintos territorios en los últimos años. Son los actores que en la mayoría de los casos han evitado que se deteriore más o se pierdan definitivamente los vestigios del ferrocarril.

Las diversas acciones de recuperación y puesta en valor de la memoria ferroviaria a nivel local, se han visto, no obstante, obstaculizadas o disminuidas por el rol fluctuante y contradictorio que ha ocupado la empresa de ferrocarriles (EFE) y las entidades públicas en las diversas acciones.

Mientras EFE enajenaba terrenos y bienes, cerraba ramales y desmantelaba vías, paralelamente otros organismos públicos apoyaban acciones de puesta en valor, rescate y preservación del patrimonio ferroviario. La ya sabida descoordinación intergubernamental y el alejamiento de ésta respecto a las necesidades y demandas de los territorios se expresa también en la construcción del discurso del patrimonio ferroviario.

EFE en los últimos años ha recogido iniciativas de puesta en valor a las cuales antes se resistía, eso es positivo, pero no ha estado exento de conflictos, porque en algunos casos este interés no se instala como un apoyo a los actores locales que están realizando acciones sino más bien como un interés centralista por asumir el control de estos procesos.

Esto último debido al declarado interés de EFE por apoyar acciones de preservación y puesta en valor que vayan principalmente orientadas al turismo y que generan por ello rentabilidad. No existe, sin embargo, hasta hoy una política formal de EFE que exprese la voluntad de apoyar acciones en la materia que no sean vinculadas al turismo, y mientras eso sea así la posibilidad de éxito de las acciones locales de puesta en valor del patrimonio orientadas más a 
la educación, sensibilización y puesta en valor de las memorias ferroviarias, no tienen muchas proyecciones.

Las acciones de patrimonialización ferroviaria orientadas sólo hacia el turismo no consideran relevante la integración y puesta en valor de las diversas memorias ferroviarias, de los procesos conflictivos o de los hitos más relevantes que han constituido la historia y memoria del ferrocarril en los territorios. El relato ferroviario orientado exclusivamente como objeto turístico es un relato cronológico, sin actores, ni conflictos, por lo cual se sitúa al margen de las ideologías políticas y económicas que han generado las principales transformaciones en la historia ferroviaria.

Resulta entonces relevante interrogarse por analizar en qué medida las acciones institucionales y privadas de patrimonialización del ferrocarril ayudan realmente a la transmisión y preservación las memorias ferroviarias como relatos vivos de la historia ferroviaria de los territorios. La comprensión del patrimonio como expresiones materiales del pasado, enfatizan una idea desterritorializada y cosificada del patrimonio.

\footnotetext{
"La Empresa de los Ferrocarriles del Estado, en adelante EFE, contempla ofrecer la operación de un tren para pasajeros turísticos, en que utilizando material ferroviario disponible, se aproveche la infraestructura ferroviaria y se promuevan destinos de carácter turísticos, relacionados con los principales atractivos turísticos de nuestro país" (extracto licitación EFE, 2007²)
}

Rojas Carlos. Otra de ferrocarriles: cerebros grises las ofician ahora de humoristas. Periódico Pichilemu. 2007. Disponible en:http://pichilemunews.blogcindario.com/2007/09/01747-otrade-ferrocarriles-cerebros-grises-las-ofician-ahora-de-humoristas. html. (Fecha de consulta: Junio 22 del 2013)
Actualmente la Empresa de Ferrocarriles posee un área de proyectos turísticos, donde figuran los proyectos del Tren turístico de la Araucanía, Antilhue, Expreso del Recuerdo, Góndola Carril, Los Andes Rio Blanco. No obstante la mayoría de estos proyectos comenzaron a levantarse a partir de actores locales con fuerte oposición de ferrocarriles. El actual apoyo de EFE a estos programas está asociado a proyectos que tengan fundamentalmente cierta rentabilidad turística. Sin embargo, cuando los actores locales han desarrollado proyectos de rescate, preservación o puesta en valor con objetivos culturales y educativos, no han contado con el mismo apoyo de la empresa.

El apoyo de los municipios o gobiernos regionales y provinciales a las acciones de patrimonialización ferroviaria ha sido muy variable en cada región y localidad. Ha dependido muchas veces de las prioridades políticas y de las redes que los actores interesados disponen.

Recoger los diversos hitos y memorias vinculadas a la llegada, desarrollo y ocaso del ferrocarril en el territorio regional y local y generar condiciones para su difusión y puesta en valor como patrimonio cultural, involucra diversos desafíos. Uno de ellos es ir más allá de lo anecdótico y de los espacios comunes de esta historia, que son lo que generalmente se rescatan cuando se desarrollan en las acciones de puesta en valor hacia el turismo. Esta recopilación histórica selecciona lo más relevante, pero con orientación comercial, es decir, lo que puede interesar más al visitante. Es una suerte de historia sin actores ni conflictos. No da cuenta en realidad de cómo los actores y las comunidades vivieron la llegada, desarrollo y fin del ferrocarril, sino la cronología de sucesos con algunas anécdotas interesantes. 
No obstante, las tendencias actuales del turismo patrimonial apunta a entender que los proyectos de este tipo deben tener una rentabilidad económica, pero también social y cultural.

A nuestro entender asumir la historicidad de este patrimonio conlleva invocar una microhistoria, una historia crítica, que dé cuenta cómo los procesos macro, como es la instalación, desarrollo y cierre del ferrocarril, afectaron las dinámicas socioculturales y económicas de los diversos actores que poblaban un lugar. No sólo describir la cronología de los acontecimientos. La historia local se conecta con la experiencia, con lo que ha sucedido en las comunidades, en aspectos significativos para ellas. Implica destacar el sujeto y las comunidades, la subjetividad presente en los acontecimientos. Ello implica, por ejemplo, develar y dar cuenta de la historia de los trabajadores del ferrocarril, de las mujeres ferroviarias, de lo qué pasaba en los barrios ferroviarios, las problemáticas sociales y culturales asociadas al ferrocarril en las distintas etapas. Implica desapegarse de la historia cronológica, de la historia de héroes y monumentos ferroviarios, para dar cuenta también de la historia de los actores excluidos y subalternos.

Ricoeur (2004), rescata el valor del testimonio, el valor del testigo como elemento estructurador de la verdad. La memoria es un asunto del pasado y del presente. Como expresan autores como Halbswachs (2004) la memoria es tanto evocación y recuerdo, como elección e interpretación y elección de los hechos del pasado. Ello porque, según este autor, las percepciones del pasado y del presente van a la par, el testimonio no explica el pasado sino la verdad del presente, por lo cual el sentido de la memoria es la construcción de un sentido al presente.

\section{Bibliografía}

Alliende, M. 1997. Historia del Ferrocarril en Chile. Santiago: Ediciones Pehuén.

Aracena, F. 2013. La industria del cobre en las provincias de Atacama y Coquimbo y los depósitos carboníferos de Lota y Coronel. Santiago. Chile. Biblioteca Nacional de Chile. Disponible en: http: //www.memoriachilena.cl/archivos2/pdfs/MC0002462. pdf. (consultado en Febrero 2013).

Astorquiza, 0.1952. Cien Años del Carbón de Lota 18521952. Cía. Carbonera e Industrial de Lota. 1952.

Astorquiza, O. 1929. Lota. Antecedentes Históricos. Compañía Minera e Industrial de Chile Concepción. 1929

Basterrica, I. 2010. Termas de Chillán. El tren a las Termas, el motivo de su creación. Blog de Arte Máximo Beltrán. Chillan. Disponible en: http://chillanantiguo.blogspot.com/2010/10/ termas-de-chillan-el-tren-las-termas-el.html\#comment-form. (Consultado julio del 2013).

Ballart, J. 1997. El patrimonio histórico y arqueológico: valor y uso. Ariel. Barcelona, España.

Bernard, R. 2010. La Situación Económico-Política de los
Ferrocarriles del Estado. Cámara Chilena de la Construcción. Edic. Universidad católica de Chile. Santiago de Chile.

Cartens, C. 2011. Rememorando Dichato. Un paseo por paisajes y relatos. Santiago. Fondo Nacional de Desarrollo Cultura y Artes. 2011.

Cartes, A. 2011. El tren chico a las Termas. Revista Tell. Concepción. Disponible en: http://www.tell.cl/magazine/4681/ concepcion/agosto/2011/columnas/el-tren-chico-a-las-termas. html. (Consultado mayo del 2013).

Casanelles, E. 2007. "Nuevo concepto de Patrimonio Industrial: evolución de su valoración, significado y rentabilidad en el contexto internacional". Revista Bienes Culturales. Instituto del Patrimonio Histórico Español. Barcelona.

CEPAL. 2012. Perfiles de Infraestructura y Transporte en América Latina. Caso Chile. Unidad de Servicios de Infraestructura. Santiago. Disponible en: www.cepal.org/perfil/noticias/ noticias/7/29957/Caso_Chile.pdf. (Consultado, Mayo 2013)

Cirese, A. 2005. "Cultura hegemónica y culturas subalternas". Teoría y análisis de la Cultura (2) Giménez, G. México: Ediciones 
Conaculta.

Delgado, F. 2012. "Tan lejos, tan cerca... auge y decadencia en la frontera carbonífera. El caso de Curanilahue y Lebu. 18801930". Revista de Historia Social y de las Mentalidades. 16 (1): 139-169.

Etchepare, J. Et. Al. 1986. Historia de Curanilahue, la búsqueda de un destino. Universidad de Concepción. Concepción.Chile.

Ferrocarriles del Estado. 1962. Guía del Veraneante 1962, Talleres Gráficos de Ferrocarriles del Estado.

Florescano, E. 1994. Patrimonio y política cultural de México: los desafíos del presente y de futuro. En Cama Jaime y Witker Rodrigo. Memoria del simposio patrimonio y política cultural para el siglo XXI. INAH. México.

Galvao, L. 2010. "Turismo y Patrimonio Ferroviario. Un estudio sobre el Trem da Vale". Revista Estudios y perspectivas sobre turismo. (19): 394-408.

García, N. 1999. Los usos sociales del Patrimonio Cultural". Aguilar, E. (Coord).

Ediciones Grijalbo.

1987. Políticas Culturales en América Latina. México:

Giménez, G. 2005. Teoría y análisis de la Cultura. México: Ediciones Conaculta.

Grallert, F. 2013. Antilhue: ferrocarril, modo de vida y erradicación. AUS. Valdivia №14 Valdivia.

Guajardo, G. 2007. Tecnología, Estado y Ferrocarriles en Chile, 1850-1950. Fundación de los Ferrocarriles Españoles. Universidad Nacional Autónoma de México.

Guerrero, R. 2012. "Patrimonio cultural mundial, territorio y construcción de ciudadanía. Construcción y apropiación social del patrimonio cultural de la ciudad de Valparaíso-Chile". Scripta Nova. Revista Electrónica de Geografía y Ciencias Sociales. Disponible en: http://www.ub.edu/geocrit/sn/sn-388.htm. Barcelona: Universidad de Barcelona. (Consultado Marzo 2014).
Halbwachs, M. 2001. La memoria Colectiva. Argentina: Miño y Dávila Editores. . 2004. Los marcos sociales de la Memoria. España:

Ediorial Anthropos.

Hermosilla, C. 2002. Historia del Ferrocarril Lebu-Los Sauces. Cañete, crónica de cinco siglos. Cañete: Editorial Cosmigonon.

Ibarra, C. et. al. 2004. Sesenta años de Historia Ferroviaria en la Región del Biobio: 1870-1930. Análisis geográfico, económico y social. Seminario de Título para optar al Grado de Licenciado en Educación mención Historia y Geografía. Concepción. Universidad de Concepción.

Jelin, E. 2001. Los trabajos de la memoria. Siglo Veintiuno editores. España.

Marín, S. 1901. Estudios de los Ferrocarriles chilenos. Santiago: Imprenta Cervantes.

Pérez, M. 2000. Construcción e Investigación del patrimonio cultural. Boletín Alteridades INAH: 95-113.

Polanco, A. 2015. Trabajadores ferroviarios de la comuna de Valdivia y la construcción de su identidad en torno a la empresa de ferrocarriles del Estado (EFE), 1973-1993. Tesis para optar al título de Profesor de Historia y Ciencias Sociales y Licenciado en Historia. Universidad Austral de Chile. Valdivia.

Prats, LI. 2004. Antropología y Patrimonio. Barcelona: Edit. Ariel S.A.

Ricoeur, P. 2004. La memoria, la historia, el olvido. Buenos Aires: Fondo de Cultura Económica.

Thompson, I. y Angerstein D. 2000. Historia del ferrocarril en Chile. Centro Barros Arana. Dirección de Bibliotecas, Archivos y Museos, Santiago.

Torres, C. 2013. Los riesgos por el "abandono cultural" del patrimonio industrial: maestranzas ferroviarias en Chile. Apuntes, 26(2): 52-67. Disponible en: http://dx.doi.org/10.11144/Javeriana. APC26-2.rabp. Revisado: mayo 2015. 